\title{
Avaliação nutricional e energética do farelo de girassol para aves
}

[Nutritional and energetic evaluation of sunflower meal in broiler diets]

\author{
F.C. Tavernari ${ }^{1}$, R.L. Morata ${ }^{1}$, V. Ribeiro Júnior ${ }^{2}$, L.F.T. Albino ${ }^{3}$, W.M. Dutra Júnior ${ }^{4}$, H.S. Rostagno ${ }^{3}$ \\ ${ }^{1}$ Aluno de pós-graduação - UFV - Viçosa, MG \\ ${ }^{2}$ Aluno de graduação - UFV - Viçosa, MG \\ ${ }^{3}$ Departamento de Zootecnia - UFV - Viçosa, MG \\ ${ }^{4}$ Departamento de Zootecnia - UFRPE - Recife, PE
}

\begin{abstract}
RESUMO
Foram realizados dois ensaios de metabolismo a fim de determinar a energia metabolizável aparente (EMA), por meio do método de coleta total de excretas com frangos, e a energia metabolizável verdadeira (EMV) e a digestibilidade verdadeira dos aminoácidos do farelo de girassol, por meio do método de alimentação forçada com galos cecectomizados. No primeiro ensaio, foi utilizado o delineamento experimental inteiramente ao acaso com 80 frangos Cobb, distribuídos em dois tratamentos, ração referência (RR) e RR mais $20 \%$ de inclusão de farelo de girassol e oito repetições e cinco aves por unidade experimental. No segundo ensaio, foi utilizado o delineamento experimental inteiramente ao acaso com 14 galos Leghorn, distribuídos em dois tratamentos, farelo de girassol e jejum, sete repetições e um galo por unidade experimental. $\mathrm{O}$ farelo de girassol apresentou $90,0 \%$ de matéria seca, $28,1 \%$ de proteína bruta, $4.42 \mathrm{kcal} / \mathrm{kg}$ de energia bruta, $22,4 \%$ de fibra bruta, $2,9 \%$ de extrato etéreo, $0,8 \%$ de fósforo e $0,3 \%$ de cálcio. A EMV, a EMV corrigida, a EMA e a EMA corrigida determinadas foram $3.013 ; 2.200 ; 2.141$ e $1.983 \mathrm{kcal} / \mathrm{kg}$, respectivamente. A lisina foi o aminoácido essencial que apresentou a menor digestibilidade e a arginina, a maior.
\end{abstract}

Palavras-chave: frango de corte, alimento alternativo, aminoácido, digestibilidade, energia metabolizável

\begin{abstract}
Two experiments were carried out to determine apparent metabolizable energy (AME), by the method of total excreta collection using broilers; and true metabolizable energy (TME) and true amino acid digestibility of sunflower meal (SFM), by the method of forced feeding using cecectomized roosters. In the first experiment, a completely randomized experimental design, with two treatments (reference diet (RD) and RD plus $20 \%$ SFM inclusion) with eight replicates of five birds each, was applied. In the second experiment, a completely randomized experimental design, with two treatments (SFM vs. fasting) with seven replicates of one rooster each, was used. Sunflower meal presented 90,0\% dry matter, $28.1 \%$ crude protein, 4,429kcal/kg crude energy, $22.4 \%$ crude fiber, $2.9 \%$ ether extract, $0.8 \%$ phosphorus, and $0.3 \%$ calcium. TME, nitrogen-corrected TME, $A M E$, and nitrogen-corrected AME were: 3,013; 2,200; 2,141; and 1,983 kcal/kg, respectively. Lysine was the essential amino acid that presented the lowest digestibility, and arginine, the highest. It is important to constantly upgrade energy and nutrient values of feedstuffs used in feed formulation to supply poultry nutritional requirements.
\end{abstract}

Keywords: broiler chickens, alternative feedstuffs, amino acids, digestibility, metabolizable energy

\section{INTRODUÇÃO}

No Brasil, o milho e o farelo de soja são componentes básicos na alimentação de frangos de corte (Oliveira et al., 2003). No entanto, a disponibilidade destes grãos é variável em função da região e época do ano, levando, assim, a variações nos custos dessa matéria-prima e afetando diretamente a lucratividade na avicultura. Dessa forma, uma alternativa para otimizar a rentabilidade na produção animal é o uso de alimentos alternativos em substituição parcial ao milho e ao farelo de soja.

Recebido em 10 de setembro de 2008

Aceito em 28 de dezembro de 2009

E-mail: fetavernari@yahoo.com.br 
O farelo de girassol é um subproduto que pode ser utilizado como fonte proteica em rações para frangos de corte (Rad e Keshavarz, 1976; Furlan et al., 2001; Oliveira et al., 2003), mas, segundo Senkoylu e Dale (1999), devido ao baixo teor de lisina e elevado de fibra, sua inclusão em rações para aves é limitada. O teor elevado de fibra presente no alimento diminui $\mathrm{o}$ valor de energético e o aproveitamento dos nutrientes pelos não ruminantes (Café, 1993).

De acordo com Villamide e San Juan (1998), problemas adicionais para o uso do farelo de girassol em dietas para aves é a escassez de informações sobre a sua composição nutricional e a variabilidade das composições encontradas na literatura.

Segundo Nery et al. (2007), solo, clima, cultivar e método de processamento, entre outros, determinam a composição nutricional e energética dos alimentos e subprodutos. Assim, é importante a constante atualização dos ingredientes que podem ser utilizados na alimentação animal, com a finalidade de atender às exigências nutricionais e à redução dos custos das rações para as aves.

Este trabalho teve os objetivos de determinar a composição bromatológica, a energia metabolizável aparente e verdadeira e a digestibilidade dos aminoácidos do farelo de girassol para aves.

\section{MATERIAL E MÉTODOS}

No primeiro ensaio, foram utilizados 80 frangos Cobb, de 18 a 28 dias de idade e média de peso corporal de $653 \mathrm{~g}$ para estimar o coeficiente de digestibilidade aparente da matéria seca (CDAMS), a energia metabolizável aparente (EMA) e corrigida (EMAn) e o coeficiente de metabolizabilidade aparente da energia bruta (CMAE) em relação à EMAn do farelo de girassol, utilizando a técnica da coleta total de excretas. Os animais foram distribuídos em um delineamento inteiramente ao acaso, com dois tratamentos, oito repetições e cinco aves por unidade experimental. Os tratamentos foram ração referência $(\mathrm{RR})$, à base de milho e de farelo de soja, formulada para atender às exigências nutricionais das aves segundo Rostagno et al. (2005) (Tab. 1), e ração teste (RR mais a inclusão de $20 \%$ de farelo de girassol). O farelo de girassol foi obtido por meio do processo que utiliza solvente para a remoção do óleo, e as sementes foram utilizadas com casca no processo de extração.

Tabela 1. Composição percentual e química da ração referência (base na matéria natural) usada para determinação da energia metabolizável para frangos de corte

\begin{tabular}{|c|c|}
\hline Ingrediente & $\%$ \\
\hline Milho & 67,45 \\
\hline Farelo de soja & 26,26 \\
\hline Óleo de soja & 2,26 \\
\hline Fosfato bicálcico & 1,67 \\
\hline Calcário & 0,86 \\
\hline Sal comum & 0,47 \\
\hline DL-metionina, $99 \%$ & 0,26 \\
\hline L-lisina $\mathrm{HCl}, 99 \%$ & 0,33 \\
\hline L-treonina, $98 \%$ & 0,11 \\
\hline Mistura vitamínica $^{1}$ & 0,10 \\
\hline Mistura mineral $^{2}$ & 0,05 \\
\hline Cloreto de colina, $60 \%$ & 0,10 \\
\hline Anticoccidiano (salinomicina, $12 \%$ ) & 0,06 \\
\hline Antioxidante $^{3}$ & 0,01 \\
\hline \multicolumn{2}{|l|}{ Composição calculada } \\
\hline Energia metabolizável, kcal/kg & 3.100 \\
\hline Energia metabolizável, $\mathrm{kcal} / \mathrm{kg}^{4}$ & 3.083 \\
\hline Proteína bruta, \% & 18,00 \\
\hline Proteína bruta, $\%^{4}$ & 17,60 \\
\hline Cálcio, \% & 0,82 \\
\hline Fósforo disponível, \% & 0,41 \\
\hline Lisina digestível, \% & 1,07 \\
\hline Metionina + cistina digestível, $\%$ & 0,77 \\
\hline Treonina digestível, \% & 0,70 \\
\hline Triptofano digestível, $\%$ & 0,19 \\
\hline \multicolumn{2}{|c|}{$\begin{array}{l}{ }^{1} \text { Mistura vitamínica }(\mathrm{kg} \text { do produto)=: vit.A } \\
\text { 10.000.000UI.; vit.D3: } 2.000 .000 U \mathrm{UI} \text {; vit.E: } 30.000 \mathrm{UI} \text {; } \\
\text { vit.B1: 2,0g; vit.B2: } 6,0 \mathrm{~g} \text {; vit.B6: 4,0g; vit.B12 } \\
\text { 0,015g; ác. pantotênico: } 12,0 \mathrm{~g} \text {; biotina: } 0,1 \mathrm{~g} \text {; vit.K3 } \\
\text { 3,0g; ác. fólico: } 1,0 \mathrm{~g} \text {; ác. nicotínico: 50,0g; Se: } \\
\text { 250,0mg. } \\
{ }^{2} \text { Mistura mineral (kg do produto)= Fe: } 80 \mathrm{~g} \text {; } \mathrm{Cu}: 10 \mathrm{~g} \text {; } \\
\text { Co: } 2 \mathrm{~g} \text {; Mn: } 80 \mathrm{~g} \text {; Zn: } 50 \mathrm{~g} \text {;: } 1 \mathrm{~g} \text {. } \\
{ }^{3} \text { Antioxidante: BHT (Butil hidroxi tolueno). } \\
{ }^{4} \text { Valor determinado (Laboratório de Nutrição Animal } \\
\text { Departamento de Zootecnia - UFV). }\end{array}$} \\
\hline
\end{tabular}

A temperatura média registrada durante $\mathrm{O}$ experimento foi de $24,0^{\circ} \mathrm{C}$, sendo 21,0 e $27,0^{\circ} \mathrm{C}$ de mínima e máxima, respectivamente.

Os pintos, alojados em um galpão de alvenaria do primeiro ao $17^{\circ}$ dia de idade, foram posteriormente transferidos para gaiolas de metabolismo, onde foi realizado o ensaio 
biológico. O período experimental foi de 10 dias, cinco dias de adaptação das aves às condições experimentais e cinco dias de coleta de excretas, com início e término em horário preestabelecido. As coletas de excretas foram realizadas duas vezes ao dia, em intervalos de 12 horas. Para evitar contaminação e perda de amostras experimentais, as bandejas colocadas sob o piso de cada unidade experimental foram revestidas com plástico.

As excretas coletadas foram colocadas em sacos plásticos, devidamente identificadas, pesadas e armazenadas em freezer. Ao final do período de coleta, as excretas foram homogeneizadas e delas retiradas alíquotas, que foram colocadas em estufa de circulação forçada a $55^{\circ} \mathrm{C}$ para présecagem. Posteriormente, foram realizadas as análises laboratoriais, segundo técnicas descritas por Silva e Queiroz (2002).

Ao término do experimento, foi determinada a quantidade de ração consumida por unidade experimental durante os cinco dias de coleta. Uma vez obtidos os resultados das análises laboratoriais dos alimentos, da ração referência, da ração teste e das excretas, foram calculados os valores de EMA e de EMAn, por meio de equações propostas por Matterson et al. (1965).

No segundo ensaio, foi utilizado o método de alimentação forçada (Sibbald, 1976) com 14 galos Leghorn, adultos cecectomizados, com média de peso de 2,280kg, para estimar o coeficiente de digestibilidade verdadeiro da matéria seca (CDVMS), a energia metabolizável verdadeira (EMV) e corrigida (EMVn), o coeficiente de metabolizabilidade verdadeiro da energia bruta (CMVE), em relação à EMVn, e a digestibilidade verdadeira dos aminoácidos do farelo de girassol. A cirurgia de cecectomia dos galos foi realizada segundo Pupa et al. (1998), usando-se anestesia local e laparatomia abdominal.

Foi utilizado o delineamento experimental inteiramente ao acaso, com dois tratamentos e sete repetições constituídas por um galo cada. Os tratamentos consistiram do farelo de girassol e do jejum para determinação das perdas endógenas e metabólicas dos aminoácidos.

Os galos, alojados em gaiolas individuais de baterias metálicas, receberam, durante o período de adaptação de cinco dias, alimentação em dois turnos de uma hora cada, pela manhã e à tarde, com o objetivo de dilatar o papo. Posteriormente, foram submetidos a um período de jejum de 36 horas, para esvaziar o trato digestivo. Após o jejum, foram forçados a consumir $30 \mathrm{~g}$ do alimento teste, por meio de um funil, via esôfago até o papo, dividido em duas amostras, fornecidas às 7 e 17h, a fim de evitar regurgitações.

A coleta total de excretas foi feita em intervalos de 12 horas, em bandejas revestidas com plástico, acondicionadas ao piso da gaiola de cada galo, por um período de 56 horas após o fornecimento da primeira porção do alimento. $\mathrm{O}$ material recolhido foi identificado, quantificado e armazenado em congelador a $-20^{\circ} \mathrm{C}$. Ao final do período de coleta, as amostras foram liofilizadas e homogeneizadas, o que permitiu a determinação dos valores de matéria seca, energia bruta e nitrogênio total, juntamente com as amostras dos alimentos. Essas análises seguiram as metodologias descritas por Silva e Queiroz (2002).

Conhecendo-se as quantidades de aminoácidos ingeridos e excretados, bem como a fração endógena obtida com galos em jejum, foi determinado o coeficiente de digestibilidade verdadeira de cada aminoácido do farelo de girassol, utilizando a fórmula proposta por Rostagno e Featherston (1977).

\section{RESULTADOS E DISCUSSÃO}

Os valores da composição bromatológica do farelo de girassol (Tab. 2) diferiram dos apresentados pelo NRC (Nutrient ..., 1998) e por Mantovani et al. (1999). Segundo Freitas et al. (2004), além de fatores como solo, clima e cultivar, no caso do farelo de girassol, outro fator importante a ser considerado para a composição é o processamento, destacando-se o método de extração do óleo e a quantidade de casca no farelo.

O valor da proteína bruta (PB) do farelo de girassol utilizado neste trabalho foi próximo aos apresentados pela Embrapa (Tabela..., 1991), Stringhini et al. (2000) e Sauvant et al. (2004) de, respectivamente, 28,5, 27,4 e 27,7\%. 
Tabela 2. Composição bromatológica do farelo de girassol usado para frangos de corte

\begin{tabular}{lc}
\hline Item & $\begin{array}{c}\text { Farelo de } \\
\text { girassol }\end{array}$ \\
\hline Matéria seca, \% & 89,95 \\
Proteína bruta, \% & 28,09 \\
Energia bruta, kcal/kg & 4.429 \\
Fibra bruta, \% & 22,37 \\
Fibra em detergente ácido, \% & 45,19 \\
Fibra em detergente neutro, \% & 21,35 \\
Extrato etéreo, \% & 2,87 \\
Cinzas, \% & 5,67 \\
Fósforo total, \% & 0,83 \\
Cálcio, \% & 0,30 \\
\hline
\end{tabular}

CDAMS, CDVMS, EMA, EMAn, EMV, EMVn, CMAE e CMVE do farelo de girassol, expressos na matéria natural, são apresentados na Tab. 3.

O valor de CMAE encontrado neste trabalho, $44,8 \%$, foi mais elevado que o apresentado por Mantovani et al. (1999), 36,9\%, para o farelo de girassol com $34,1 \%$ de PB e $21,7 \%$ de fibra bruta.

De acordo com Leeson e Summers (2001), é necessário corrigir os valores estimados de energia pelo balanço de nitrogênio, pois, durante um ensaio de metabolismo, é impossível assegurar que todas as aves apresentem a mesma taxa de crescimento. O valor de EMA foi mais alto que o de EMAn e, segundo Nery et al. (2007), essa característica é normal quando os valores de energia metabolizável são determinados em aves em crescimento, pois nessa fase ocorre maior retenção de nitrogênio para que ocorra deposição de tecido proteico, que é mais acentuada quando se faz correção pelas perdas endógenas e metabólicas.

Valores diferentes de energia metabolizável para o farelo de girassol são encontrados na literatura. Mantovani et al. (1999), ao incluírem 20\% do alimento em uma ração referência, encontraram para EMA e EMAn 1.569 e $1.459 \mathrm{Kcal} / \mathrm{kg}$, respectivamente, enquanto Stringhini et al. (2000), ao adicionarem $40 \%$ do alimento em uma ração referência, encontraram para EMA e EMAn 1.777 e $1.523 \mathrm{Kcal} / \mathrm{kg}$, respectivamente.

A porcentagem de substituição é uma fonte de variação nas estimativas da energia metabolizável dos alimentos (Potter, 1972). Segundo Penz et al. (1999), para alguns alimentos, a substituição acima dos teores de inclusão utilizados normalmente nas rações de produção pode subestimar os valores de energia dos alimentos. Segundo Sakomura e Rostagno (2007), para alimentos com alto teor de fibra, recomenda-se substituir $20 \%$ da ração referência para determinar a EMA pelo método de coleta total de excretas.

Tabela 3. Coeficientes de digestibilidade aparente e verdadeiro da matéria seca (CDAMS e CDVMS), energia metabolizável aparente e corrigida (EMA e EMAn), energia metabolizável verdadeiro e corrigida (EMV e EMVn) e coeficientes de metabolizabilidade aparente e verdadeira da energia bruta (CMAE e CMVE) do farelo de girassol, expressos na matéria natural, e seus respectivos desvios-padrão da média, obtidos de frangos de corte

\begin{tabular}{lc}
\hline Item & Farelo de girassol \\
\hline CDAMS, \% & $39,05 \pm 2,63$ \\
EMA, Kcal/kg & $2.141 \pm 140$ \\
EMAn, kcal/kg & $1.983 \pm 137$ \\
CMAE, \% & $44,77 \pm 2,79$ \\
\hline CDVMS, \% & $60,29 \pm 4,31$ \\
EMV, Kcal/kg & $3.013 \pm 192$ \\
EMVn, kcal/kg & $2.200 \pm 228$ \\
CMVE, \% & $48,05 \pm 4,40$ \\
\hline
\end{tabular}

Os valores de EMA e de EMAn encontrados foram próximos aos apresentados por Freitas et al. (2004), que incluíram $20 \%$ de farelo de girassol em uma ração referência à base de milho e de farelo de soja, 2.216 e 1.902, respectivamente. $\mathrm{O}$ valor de EMAn foi mais alto que os $1.320 \mathrm{Kcal} / \mathrm{kg}$ apresentados por Sauvant et al. (2004) para o farelo de girassol com $27,7 \%$ de $\mathrm{PB}$ e $1.200 \mathrm{Kcal} / \mathrm{kg}$ para o farelo de girassol com $30 \%$ de PB apresentado pela FEDNA (Tablas..., 2003).

De acordo com Rostagno et al. (2005), o farelo de soja com $45 \%$ de PB apresenta $4.079 \mathrm{Kcal}$ de energia bruta (EB) e 2.256 de EMAn, ou seja, menor EB e maior EMAn que o farelo de girassol avaliado. Segundo Freitas et al. (2004), a presença de fibra solúvel no farelo de girassol pode aumentar a viscosidade intestinal, dificultando a digestão e a absorção dos nutrientes, principalmente dos lipídios, o que resulta em menor aproveitamento da energia.

Existem poucos estudos sobre a EMV do farelo de girassol. Villamide e San Juan (1998) 
testaram 11 amostras diferentes de farelo de girassol de elevada proteína bruta com galos não cecectomizados. O menor valor da proteína bruta foi de $31,5 \%$ e o maior, $41,7 \%$, com base na matéria seca, e estes apresentaram $1.558 \mathrm{Kcal} / \mathrm{kg}$ e $2.023 \mathrm{Kcal} / \mathrm{kg}$ de EMVn na matéria seca, respectivamente. $\mathrm{O}$ farelo de girassol avaliado neste trabalho apresentou maior EMVn na matéria seca do que os valores apresentados por Villamide e San Juan (1998).

$\mathrm{Na}$ Tab. 4, são apresentados os valores de aminoácidos totais (AA totais), coeficientes de digestibilidade verdadeira (CDV) e aminoácidos digestíveis (AA Dig). A arginina foi $\mathrm{o}$ aminoácido essencial que apresentou o maior coeficiente de digestibilidade, 91,6\%, enquanto a lisina foi o que apresentou o menor, 81,2\%. Estes valores são mais baixos que os coeficientes de digestibilidade da arginina, 96,0\%, e da lisina, $92,2 \%$, do farelo de soja com $45 \%$ de PB apresentados por Rostagno et al. (2005). Em revisão sobre o uso do farelo de girassol na avicultura, Senkoylu e Dale (1999) relataram que o farelo de girassol tem como fator limitante para seu uso na avicultura o baixo teor de lisina.

No presente trabalho, o teor de lisina digestível foi de $0,68 \%$, o que pode ser considerado baixo quando comparado com o farelo de soja que continha $45 \%$ de PB apresentado por Rostagno et al. (2005), e que apresentava 2,55\% de lisina digestível. Atualmente, este não é um fator limitante para seu uso na avicultura de corte, uma vez que é comumente utilizada a suplementação com aminoácido sintético nas dietas. O teor de lisina total encontrado no presente trabalho $(0,84 \%)$ é mais baixo que os valores apresentados pela Embrapa (Tabela..., 1991), Stringhini et al. (2000) e Sauvant et al. (2004), de 0,$90 ; 0,95 \%$ e $1,00 \%$, respectivamente.

Tabela 4. Aminoácidos totais (AA totais), coeficientes de digestibilidade verdadeiros (CDV) e aminoácidos digestíveis (AA Dig) do farelo de girassol para frangos de corte (na matéria natural)

\begin{tabular}{lccc}
\hline \multicolumn{1}{c}{ Aminoácido } & AA totais & CDV & AA Dig. \\
\hline Lisina (\%) & \multicolumn{2}{c}{ Aminoácidos essenciais } & 0,68 \\
Metionina (\%) & 0,84 & 81,16 & 0,54 \\
Metionina+Cistina (\%) & 0,61 & 88,71 & 0,92 \\
Treonina (\%) & 1,09 & 84,72 & 0,82 \\
Arginina (\%) & 1,00 & 82,14 & 2,08 \\
Histidina (\%) & 2,27 & 91,61 & 0,57 \\
Valina (\%) & 0,66 & 85,84 & 1,14 \\
Isoleucina (\%) & 1,33 & 85,67 & 0,97 \\
Leucina (\%) & 1,10 & 88,18 & 1,50 \\
Fenilalanina (\%) & 1,70 & 88,27 & 1,13 \\
Glicina (\%) & 1,28 & 88,39 & --- \\
\hline & 1,60 & --- & 0,37 \\
Cistina (\%) & Aminoácidos não essenciais & 0,98 \\
Alanina (\%) & 0,47 & 77,81 & 2,13 \\
Ac. Aspártico (\%) & 1,18 & 83,41 & 4,97 \\
Ac. Glutâmico (\%) & 2,52 & 84,54 & 0,96 \\
Serina (\%) & 5,49 & 90,59 & 0,66 \\
Tirosina (\%) & 1,19 & 81,12 & 85,53 \\
\hline
\end{tabular}

\section{CONCLUSÕES}

O farelo de girassol avaliado apresenta EMV, EMVn, EMA e EMAn de 3.013; 2.200; 2.141 e $1.983 \mathrm{kcal} / \mathrm{kg}$, respectivamente. O coeficiente de digestibilidade e o teor de lisina digestível do farelo de girassol são mais baixos que os dos farelo de soja.

\section{AGRADECIMENTOS}

Ao Programa de Cooperação Acadêmica (PROCAD/CAPES), pela possibilidade de realização do mestrado sanduíche, e à Bunge Alimentos, pelo fornecimento do farelo de girassol. 


\section{REFERÊNCIAS BIBLIOGRÁFICAS}

CAFÉ, M.B. Estudo do valor nutricional da soja integral processada para aves. 1993. 97f. Dissertação (Mestrado) - Universidade Estadual Paulista, Jaboticabal, SP.

FREITAS, E.R.; SAKOMURA, N.V.; NEME, R. et al. Determinação da digestibilidade dos nutrientes e da energia metabolizável da semente e do farelo de girassol para frangos de corte. In. REUNIÃO ANUAL DA SOCIEDADE BRASILEIRA DE ZOOTECNIA, 41., 2004, Campo Grande. Anais... Campo Grande: SBZ, 2004. p.1-4. (Resumo).

FURLAN, A.C.; MANTOVANI, C.; MURAKAMI, A.E. et al. Utilização do farelo de girassol na alimentação de frangos de corte. Rev. Bras. Zootec., v.30, p.174-175, 2001.

LEESON, S.; SUMMERS, J.D. Scott's nutrition of the chicken. 4.ed. Guelph: University Books, 2001. 591p.

MANTOVANI, C.; FURLAN, A.C.; MURAKAMI, A.E. et al. Composição química e valor energético do farelo e da semente de girassol para frangos de corte. In. REUNIÃO ANUAL DA SOCIEDADE BRASILEIRA DE ZOOTECNIA, 36., 1999, Porto Alegre. Anais... Porto Alegre: SBZ, 1999. p.189. (Resumo).

MATTERSON, L.D.; POTTER, L.M.; STUTZ, M.W. et al. The metabolizable energy of feed ingredients for chickens. Storrs, CT: Agricultural Experiment Station, 1965. 11p. (Research Report, 7).

NERY, L.R.; ALBINO, L.F.T.; ROSTAGNO, H.S. et al. Valores de energia metabolizável de alimentos determinados com frangos de corte. Rev. Bras. Zootec., v.36, p.1354-1358, 2007.

NUTRIENT requirements of swine. 10.ed. Washington: National Academy of Sciences, 1998. 189p.

OLIVEIRA, M.C.; MARTINS, F.F.; ALMEIDA, C.V. et al. Efeito da inclusão de bagaço de girassol na ração sobre o desempenho e rendimento de carcaça de frangos de corte. Rev. Port. Zootec., v.10, p.107-116, 2003 .

PENZ JÚNIOR, A.M.; KESSLER, A.M.; BRUGALLI, I. Novos conceitos de energia para aves. In. SIMPÓSIO INTERNACIONAL SOBRE NUTRIÇÃO DE AVES, 1999, Campinas. Anais... Campinas: Fundação APINCO, 1999. p.1-24. (Resumo).

POTTER, L.M. The precision of measuring metabolizable energy in poultry feedstuffs. Feedstuffs, v.44, p.28-30, 1972.
PUPA, J.M.R.; LEÃO, M.I.; ROSTAGNO, H.S. Cecectomia em galos por incisão abdominal e anestesia local. In. CONFERENCIA APINCO DE CIÊNCIA E TECNOLOGIA AVÍCOLAS, 1998, São Paulo. Anais... Campinas: Fundação APINCO, 1998. p.87. (Resumo).

RAD, F.H.; KESHAVARZ, K. Evaluation of the nutritional value of sunflower meal and the possibility of substitution of sunflower meal for soybean meal in poultry diets. Poult. Sci., v.55, p.1757-1764, 1976.

ROSTAGNO, H.S.; ALBINO, L.F.T.; DONZELE, J.L. et al. Tabelas brasileiras para aves e suínos: composição de alimentos e exigências nutricionais. 2.ed. Viçosa: UFV, 2005. 186p.

ROSTAGNO, H.S.; FEATHERSTON, W.R. Estudos de métodos para determinação de disponibilidade de aminoácidos. Rev. Soc. Bras. Zootec., v.6, p.64-75, 1977.

SAKOMURA, N.K.; ROSTAGNO, H.S. Métodos de pesquisa em nutrição de monogástricos. Jaboticabal: FUNEP, 2007. 283p.

SAUVANT, D.; PEREZ, J.M.; TRAN, G. Tablas de composición y de valor nutritivo de las materias primas destinadas a los animales de interés ganadero: cerdos, aves, bovinos, ovinos, caprinos, conejos, caballos, peces. Madrid: Mundi-Prensa, 2004. 195p.

SENKOYLU, N.; DALE, N. Sunflower meal in poultry diets. World's Poult. Sci. J., v.55, p.153-174, 1999.

SIBBALD, I.R. A bioassay for true metabolizable energy in feedingstuffs. Poult. Sci., v.55, p.303-308, 1976.

SILVA, D.J.; QUEIROZ, C. Análise de alimentos: Métodos químicos e biológicos. Viçosa: UFV, 2002. $235 \mathrm{p}$.

STRINGHINI, J.H.; CAFÉ, M.B.; FERNANDES, C.M. et al. Avaliação do valor nutritivo do farelo de girassol para aves. Cien. Anim. Bras., v.1, p.123-126, 2000.

TABELA de composição química e valores energéticos de alimentos para suínos e aves. 3.ed. Concórdia: Embrapa/CNPSA, 1991. 97p. (Documentos, 19).

TABLAS de composición y valor nutritivo de alimentos para la fabricación de piensos compuestos. 2.ed. Madrid: FEDNA, Mundi-Prensa, 2003. 423p.

VILLAMIDE M.J.; SAN JUAN, L.D. Effect of chemical composition of sunflower seed meal on its true metabolizable energy and amino acid digestibility. Poult. Sci., v.77, p.1884-1892, 1998. 